\title{
A PESQUISA NARRATIVA NA FORMAÇÃO DE PROFESSORES: APROXIMAÇÕES QUE SE POTENCIALIZAM
}

\section{NARRATIVE INQUIRY IN TEACHER TRAINING: CLOSENESS THAT ENHANCES}

\section{LA INVESTIGACIÓN NARRATIVA EN LA FORMACIÓN DE PROFESORES: APROXIMACIONES QUE SE POTENCIALIZAN}

\author{
Fábio Mariani* \\ Professor do Instituto Federal de Educação, Ciências e Tecnologia do Mato Grosso \\ Filomena Maria de Arruda Monteiro** \\ Professora da Universidade Federal do Mato Grosso.
}

Resumo: O objetivo deste artigo é apresentar e discutir as aproximações estabelecidas entre o campo da formação de professores e a narrative inquiry, com destaque para as potencialidades que essa perspectiva metodológica trouxe para os estudos e investigações do Grupo de Estudos e Pesquisas em Política e Formação Docente (GEPForDoc), bem como apresentar resultados de uma pesquisa narrativa desenvolvida no contexto do referido grupo, que teve como objetivo compreender os sentidos construídos por um grupo de licenciandos em Física sobre as experiências formativas vivenciadas no processo de formação inicial. A pesquisa revela os dilemas enfrentados pelos licenciandos no que diz respeito a se perceberem e se aceitarem como profissionais da educação, as dificuldades na transposição de alunos para professores e as influências das experiências formativas na constituição de suas identidades docentes. Palavras-chave: Pesquisa Narrativa. Formação de Professores. Desenvolvimento Profissional.

\footnotetext{
* Mestre em Educação pela Universidade Federal de Mato Grosso; doutorando em Educação pela Universidade Federal do Mato Grosso.

** Pós-doutora pela Universidade Federal de São Carlos; Doutora em Educação pela Universidade Federal de São Carlos.
} 
Abstract: The objective of this article is to present and discuss the connections established between the field of teachers' training and the narrative inquiry, highlighting the potentialities that this methodological perspective brought to the studies and investigations of the Studies and Research Group in Policy and Teacher Training - GEPForDoc. It also aims at presenting results of a narrative research conducted in the context of this group, which aimed to understand the meanings constructed by a group of undergraduates in Physics about the formative experiences of the initial training process. The research reveals the dilemmas faced by these undergraduates in relation to perceptions and acceptance of themselves as education professionals, the difficulties in transposing from students to teachers and the influences of the formative experiences in setting up their teaching identities.

Keywords: Narrative Research. Teacher Training. Professional Development.

Resumen: El objetivo de este artículo es presentar y discutir las aproximaciones establecidas entre el campo de la formación de profesores y la narrative inquiry, haciendo énfasis en las potencialidades que esta perspectiva metodológica trajo para los estudios e investigaciones del Grupo de Estudios e Investigaciones en Política y Formación Docente - GEPForDoc, así como presentar resultados de una investigación narrativa desarrollada en el contexto del grupo mencionado, la cual tuvo como objetivo comprender los sentidos construidos por un grupo de estudiantes de Licenciatura en Física sobre las experiencias formativas vividas durante el proceso de formación inicial. El estudio revela los dilemas enfrentados por los estudiantes con respecto a si se percibieron y aceptaron como profesionales de la educación, las dificultades en la transposición de alumnos para profesores y las influencias de las experiencias formativas en la constitución de sus identidades docentes.

Palabras clave: Investigación Narrativa. Formación de Profesores. Desarrollo Profesional.

\section{INTRODUÇÃO}

As discussões que compõem o presente artigo foram constituídas a partir do movimento teórico-metodológico adotado pelo Grupo de Estudos e Pesquisas em Política e Formação Docente (GEPForDoc), constituído desde 2004 e que desenvolve estudos e pesquisas sobre formação de professores na perspectiva teórica do que se tem compreendido como "desenvolvimento profissional docente", buscando aproximações com as pesquisas narrativas enquanto método de investigação, visando cons- 
truir um referencial de pesquisa que potencialize e traduza as suas concepções acerca do campo de investigação no qual se encontra envolvido.

Sendo assim, objetiva-se discutir as aproximações estabelecidas entre o campo da formação de professores e a pesquisa narrativa, com destaque para a compreensão das potencialidades que essa perspectiva teórico-metodológica traz para os estudos e investigações no contexto do grupo de pesquisa, bem como apresentar resultados de uma pesquisa narrativa desenvolvida no contexto do grupo.

Como forma de organização do texto, a primeira parte estabelece discussões sobre os referenciais da formação de professores e as aproximações com a pesquisa narrativa, para, no segundo momento, discutir o contexto e os resultados da pesquisa.

\section{DIÁLOGOS ENTRE A FORMAÇÃO DE PROFESSORES E A PESQUISA NARRATIVA}

Partindo do entendimento de que o desenvolvimento profissional docente pressupõe um processo de evolução e continuidade, superando a ideia de simples justaposição ou somatórias de diferentes e distintas etapas formativas, na forma de uma linearidade estática e mecânica (GARCIA, 1995, 1999; MIZUKAMI et al., 2006; IMBERNÓN, 2009; VAILLANT; GARCIA, 2012), compreende-se que a formação, na perspectiva dos processos contínuos, compreendidos a partir do contexto do desenvolvimento profissional, pressupõe uma dinâmica e complexa articulação de todas as etapas em que "a formação vai e vem, avança e recua, construindo-se no interior de um processo de relação ao saber e ao conhecimento que se encontra no cerne da identidade pessoal." (NÓVOA, 1995, p. 25). Também se torna importante a compreensão de que fatores cognitivos, afetivos, éticos, crenças e valores, a própria atuação e o contexto, entre outros aspectos, influenciam as aprendizagens da docência ao longo da carreira e precisam ser tomados enquanto fatores importantes no pensar a formação de professores.

Tal compreensão se alicerça na ideia de que os processos de formação de professores precisam ser compreendidos no movimento que caracteriza o desenvolvimento profissional docente, entendendo "[...] que a formação tenha como eixo de referência o desenvolvimento profissional de professores na dupla perspectiva do professor individual e do coletivo docente." (NÓVOA, 1995, p. 24, grifo do autor). Nesse sentido - das dimensões individuais e coletivas, subjetivas e intersubjetivas, pessoais e relacionais - os processos formativos dos professores precisam ser pensados e articulados no/com os contextos das escolas e de seus projetos, para que se garanta a efetividade do desenvolvimento profissional docente em seus múltiplos aspectos. A 
formação, assim compreendida, assume uma dupla perspectiva: a individual e a relacional, em que "a troca de experiências e a partilha de saberes consolidam espaços de formação mútua, nos quais cada professor é chamado a desempenhar, simultaneamente, o papel de formador e de formando.” (NÓVOA, 1995, p. 26).

Pensar a formação de professores tendo por base os autores citados requer um olhar atento para suas dimensões formativas pessoais e coletivas, no que se refere aos percursos e trajetórias pessoais e profissionais. Nesse sentido, a formação precisa ser compreendida para além de esquemas baseados no acúmulo de cursos, de técnicas de ensino, de dinâmicas de facilitação da memorização de determinado conjunto de conteúdos. Antes disso, a formação precisa ser compreendida como um " [...] trabalho de reflexividade crítica sobre as práticas e de (re) construção permanente de uma identidade pessoal. Por isso, é importante investir na pessoa e dar um estatuto ao saber da experiência." (NÓVOA, 1995, p. 25, grifo do autor). Partindo de tais discussões, o grupo busca encontrar novas formas de se estudar o desenvolvimento profissional de professores a partir da "experiência/sentido".

Assim, tomar a anunciada perspectiva de desenvolvimento profissional de professores levou os integrantes do grupo, enquanto pesquisadores vinculados à universidade, a uma necessária aproximação e diálogo com o contexto das escolas. Tinha-se em mente que não seria possível desenvolver pesquisas e produção de conhecimentos a partir dessa perspectiva, ficando do lado de dentro dos muros da universidade. Era clara a necessidade de compreender os contextos e lugares onde os professores se inserem e nos quais desenvolvem suas ações, desencadeiam reflexões, constroem conhecimentos e potencializam sua formação contínua. O olhar precisaria ser construído a partir da perspectiva dos atores do processo formativo, ou seja, pesquisadores, gestores e os próprios professores. Para isso, tornou-se necessário estabelecer aproximação, interação e o mergulho intersubjetivo entre aqueles que pesquisam e os que colaboram com a pesquisa, agora chamados a atuar como sujeitos participativos, ativos e com voz.

Partindo dessa perspectiva, o grupo, desde sua constituição, vem despendendo esforços na construção de bases teórico-metodológicas capazes de embasar as pesquisas, aproximando e permitindo o desenvolvimento de investigações afinadas com a compreensão construída sobre os processos de formação de professores. Ao buscar tais referenciais, o grupo intentou a construção de um movimento articulador entre o campo teórico e o metodológico, a fim de tornar sólida, coerente e consistente a produção do conhecimento nessa perspectiva. Para isso, os referenciais metodológicos precisam se despir de alguns cânones tradicionais da pesquisa científica, caracteri- 
zados pela prescrição de objetividade, neutralidade e dos critérios de validação de verdades universalizantes, para se aproximar subjetivamente do lócus de onde se nutre a formação. A intenção se constrói a partir de uma nova modalidade de se fazer pesquisa, que, não negligenciando o rigor e a profundidade da produção do conhecimento, seja capaz de romper com a perspectiva mais formalista de pesquisa, voltando o olhar para a possibilidade de um conhecimento construído a partir da experiência vivenciada no dia a dia da escola, na subjetividade das relações e das percepções daqueles que vivem as contradições cotidianas que envolvem o processo ensino-aprendizagem.

Nesse movimento, o grupo buscou aproximação com as metodologias que se vinham constituindo a partir dos chamados movimentos biográficos e autobiográficos (NÓVOA; FINGER, 2010; SOUZA, 2006) e encontrou, nas discussões das pesquisas com narrativas as prerrogativas almejadas. Por certo período, o grupo, ainda em fase de aprofundamento de estudos centrados nos referenciais metodológicos, assumiu as narrativas enquanto instrumento de coleta de dados para a pesquisa, produções e publicações.

No entanto, no decorrer desse processo, percebeu-se a existência de várias perspectivas de estudos que tomavam as narrativas dos sujeitos como ponto central das investigações, guardadas suas particularidades, abordagens e diversidades no que diz respeito às perspectivas teórico-metodológicas (MELLO, 2004, 2010). Nesse sentido, com o aprofundamento dos estudos, assumiu-se, no contexto do grupo, a perspectiva da Pesquisa Narrativa compreendida como método de pesquisa, com base nas proposições teóricas dos autores canadenses Clandinin e Connelly (2011).

A opção pela pesquisa narrativa foi se construindo à medida da compreensão de uma base epistemológica com centralidade na experiência, capaz de proporcionar a "aproximação" entre a perspectiva metodológica e a compreensão sobre a formação de professores e os contextos de desenvolvimento profissional docente.

Mello (2004) sintetiza, em seus apontamentos, os motivos que a conduziram à opção pela pesquisa narrativa enquanto sustentação metodológica dos estudos e investigações, o que permitiu vislumbrar que se trata de uma perspectiva inovadora e até subversiva e contra-hegemônica, se se tomar os cânones das pesquisas mais formalistas e tradicionais que dominam a produção de conhecimento nos espaços acadêmicos e que convergem com o adotado enquanto alicerce metodológico das pesquisas no grupo. A autora, refletindo a partir de suas próprias justificativas para o seu envolvimento com a pesquisa narrativa, afirma que:

Algumas dessas questões se relacionavam com o papel do pesquisador mais próximo e envolvido com os participantes de 
pesquisa, a linguagem menos canônica no texto acadêmico, a não apresentação de uma única verdade como resultado, mas diante das múltiplas possibilidades de interpretação, o respeito pela linha adotada pelo pesquisador, sem uma visão mais direcionada para validações e busca de verdades comprováveis. (MELLO, 2004, p. 84).

Trata-se, portanto, de uma perspectiva teórico-metodológica que responde aos propósitos de estudos no campo da formação de professores, opção do grupo de pesquisa, justamente por colocar o pesquisador mais próximo dos contextos da escola, da vivência dos processos de ensinar e aprender, característicos da profissão docente, caminhando lado a lado.

Sendo assim, a base da Pesquisa Narrativa é pautada nos fundamentos teórico-metodológicos de Connelly e Clandinin (1995); Clandinin \& Connelly (2011); Clandinin (2010); Mello (2004, 2010a, 2010b); Telles (1999); Galvão (2005) e Moreira (2011). Para esses autores, a narrative inquiry é tanto o fenômeno estudado quanto o método de pesquisa, uma vez que o "pensamento narrativo é uma forma-chave de escrever e pensar sobre ela." Cabe dizer que o método narrativo é uma parte ou aspecto do fenômeno narrativo. Assim, ele é o "fenômeno e também o método das ciências sociais." (CLANDININ; CONNELLY, 2011, p. 48).

Aproximar da pesquisa narrativa proposta por Clandinin e Connelly significa considerar o lugar ocupado por cada participante da experiência, ou seja, o contexto em que cada história acontece e a maneira pela qual as pessoas interagem com os contextos, o que envolve sentimentos, desejos e reações.

A experiência é o ponto central e básico da pesquisa narrativa (CLANDININ; CONNELLY, 2011; CONNELLY; CLANDININ, 1995; MELLO, 2004, 2010a), uma vez que "a narrativa é a estrutura fundamental da experiência humana." (TELLES, 1999, p. 80). O narrar torna-se condição essencial do ser humano, à medida que a organização do pensamento humano é narrativa, sendo a melhor forma de se pensar, construir juízos, explicitar e construir sentidos sobre as experiências vividas. Assim, compreender a experiência de outrem implica se colocar ao lado dele, dialogando com ele (GADAMER, 1997) para, por meio da indagação colaborativa, dar à mesma o lugar apropriado no contexto de ressignificações.

Ampliando essa discussão, "a razão principal para o uso da narrativa na pesquisa em educação é que nós seres humanos, somos organismos que, individual e socialmente, vivemos vidas contadas." (CONNELLY; CLANDININ, 1995, p. 11). Ao se experimentar o mundo e construir sentidos sobre as experiências, as narrativas 
tornam-se exemplares, visto se constituir na forma como os seres humanos experimentam o mundo (CONNELLLY; CLANDININ, 1995, p. 11).

No viver e contar suas histórias, as pessoas têm a oportunidade de refletir sobre si mesmas e, assim, compor sentidos que se tornam significativos para elas. Nesse movimento vão construindo suas identidades, avaliando posicionamentos, concepções, enfim, vão se firmando enquanto sujeitos. Para os pesquisadores narrativos, o importante é a forma como as pessoas - os participantes da pesquisa e o próprio pesquisador - impingem um olhar atento para si próprios, para suas histórias pessoais e experiências, e junto com os participantes vão construindo sentidos sobre as experiências que estão vivenciando, mas não só isso, é necessário que reflitam sobre a forma como organizam, problematizam e interpretam tais experiências, de forma que ganhem significação para eles, pois, tornando-se significativas, tornam-se formativas.

A pesquisa narrativa pode ser desenvolvida a partir do contar e do vivenciar histórias. O “contar de histórias" se realiza quando o pesquisador ouve as histórias dos seus colaboradores sobre as experiências que eles vivenciaram. Esse "ouvir" pode ser entendido para além da escuta da fala, no sentido literal, ou seja, o pesquisador pode se valer de textos escritos (autobiografias, documentos, cartas, diários, anotações, entre outros) compostos pelos participantes, nos quais são narrados os sentidos atribuídos sobre as experiências. Nesse caso, o pesquisador não presenciou, não observou ou não vivenciou as experiências junto com os participantes. A sua contribuição ocorre no momento do contar e construir sentidos a essas histórias. Por outro lado, na pesquisa narrativa, compreendida como "vivências das histórias", o pesquisador participa efetivamente, vivencia junto com seus participantes determinada experiência. $\mathrm{O}$ pesquisador insere-se em um determinado tempo e lugar para viver determinada experiência, não como espectador ou observador, mas como alguém que vai efetivamente interagir na experiência, estabelecendo diálogos, reflexões e questionamentos junto aos participantes. Nesse movimento, ambos vão construindo suas histórias com os sentidos atribuídos ao que estão vivenciando. Essas histórias materializam-se em textos de campo, transformados na base para as interpretações e construções de sentidos do pesquisador em textos provisórios e finais - artigos científicos, dissertação ou tese. Nesse movimento, o pesquisador vai negociando os sentidos construídos com os participantes, à medida que ambos vão vivenciando a experiência. Por isso, a pesquisa narrativa é essencialmente relacional.

Segundo a perspectiva de Clandinin e Connelly (2011), são três os lugares comuns da pesquisa narrativa que devem ser tomados, com muito cuidado, pelos pesquisadores: temporalidade, sociabilidade e lugar, os quais compõem as dimensões de 
um espaço de pesquisa. Portanto, o processo da pesquisa narrativa é demarcado por uma tridimensionalidade. Nas palavras de Clandinin (2010, p. 3), são "[...] lugares a dirigir a atenção na condução de uma pesquisa narrativa. Eles fornecem um tipo de arcabouço conceitual para a pesquisa narrativa."

A questão da temporalidade é uma dimensão importante, em razão de que os participantes da pesquisa, que vivenciam o momento presente com o pesquisador, são possuidores de uma longa história representativa de sua trajetória anterior à vivência no momento da investigação. Nessa medida, a experiência vivenciada no presente sofre, necessariamente, influência do passado, ao mesmo tempo que se projeta para um futuro. Assim, suas existências não estão condicionadas às do pesquisador, tampouco à experiência que está vivendo. Suas vidas têm um antes, um agora e terão um depois, ou seja, incluem perspectivas de passado, presente e futuro.

O segundo elemento da tridimensionalidade, a sociabilidade, aponta tanto para as "condições pessoais" quanto para as "condições sociais" dos participantes. As primeiras dizem respeito aos sentimentos, esperanças, desejos, reações estéticas, disposições morais, crenças, concepções, dentre outros aspectos, que são constituidores das individualidades e subjetividades de cada pessoa. Esta, por sua vez, é condicionadora da maneira como pensam, agem e percebem o mundo e a si mesmos (MELLO, 2004). As condições sociais se referem às "condições existenciais, o ambiente, forças e fatores subjacentes e pessoas que participam e formam o contexto dos indivíduos." (MELLO, 2004, p. 109).

O lugar - terceira dimensão ou lugar comum na pesquisa narrativa - se refere ou "direciona nossa atenção para as fronteiras específicas topológicas, físicas, e concretas de um lugar ou de uma sequência de lugares onde a pesquisa e os eventos acontecem." (CLANDININ, 2010, p. 4). Sendo assim, pensar o impacto dos lugares sobre as vidas, experiências, histórias das pessoas envolvidas em uma pesquisa narrativa, constitui tarefa muito importante para o pesquisador.

Quando se atenta para esse movimento tridimensional da pesquisa narrativa - temporalidade, sociabilidade e lugar - pode-se perceber que ele implica, necessariamente, outros dois movimentos a serem desenvolvidos, tanto pelo pesquisador quanto pelos participantes em processo de pesquisa: um movimento que implica o "olhar para si", para dentro, introspectivamente; de outro, um olhar para fora, para os contextos a sua volta, um olhar "extrospectivo" (MELLO, 2010b, p. 182). O primeiro implica que a pessoa se volte para o seu interior, para a sua subjetividade, para a constituição do "si mesmo", enquanto o segundo evoca o exterior, as intersubjetividades, as relações com o outro e com os contextos. 
Uma questão importante é apontada por Mello (2004, p. 90): a de que esses movimentos da pesquisa narrativa, "devem ser expressos não só nos procedimentos de pesquisa, mas também no texto de pesquisa." Ou seja, esse movimento torna-se a estrutura de artigos, dissertações ou teses. Eles precisam estar contemplados no texto final ou na narrativa final. Esse movimento torna-se o caminho para todo o processo de pesquisa, no engajamento nela, na composição dos textos de campo e na composição dos sentidos que demarcam as interpretações dos sentidos narrados a partir das experiências vividas. Esse conjunto de procedimentos demarca a complexidade da pesquisa narrativa, que exige um olhar e um pensar narrativos revestidos da atenção sempre despendida a esses movimentos tridimensionais - temporalidade, sociabilidade e lugar - e desse processo introspectivo, "extrospectivo". Interpretar e compor sentidos somente serão possíveis a partir desses movimentos.

Nessa medida, a Pesquisa Narrativa é "um tipo de investigação que pode criar oportunidades para que as pessoas (pesquisadores e participantes) construam suas vozes e possam construir e compor sentidos de suas próprias histórias, também importantes para entender nosso lugar nos contextos em que vivemos." (MELLO, 2004, p. 98). Assim, entendemos que se fazer ouvir, estabelecer diálogos, refletir e compor sentidos sobre as próprias histórias, a partir dos contextos nos quais se nutre e atua, tendo direito à voz, torna-se espaço privilegiado de formação. Por isso, entende-se que o processo da pesquisa narrativa é potencializador da formação/investigação, tanto para o pesquisador quanto para os participantes, encontrando nesse movimento justificativas de sua relevância política e social para o seu desenvolvimento (MOREIRA, 2011).

A seguir, serão apresentados os resultados de uma pesquisa narrativa, desenvolvida no contexto do GEPForDoc, que toma como foco a formação inicial de professores.

\section{UMA EXPERIÊNCIA FORMATIVA VIVENCIADA COM UM GRUPO DE LICENCIANDOS}

A investigação teve por base a composição de sentidos sobre uma experiência formativa vivenciada junto a um grupo de estudantes que se encontravam em processo de formação inicial de professores, no interior de um curso de licenciatura em Física. Tomaram-se as narrativas construídas pelos licenciandos enquanto textos de campo de uma pesquisa que teve por objetivo compreender os sentidos construídos por esse grupo de licenciandos sobre as experiências formativas vivenciadas no processo de formação inicial, delineando a profissão de professor. 
A pesquisa de campo ocorreu no ano letivo de 2013, período em que os licenciandos se encontravam no sétimo e oitavo semestres, correspondentes, respectivamente, aos dois últimos do curso. Para a composição dos textos de campo, tomados em seu conjunto e que compõem a narrativa de cada participante, foi estabelecido um grupo de discussão e reflexão envolvendo licenciandos e pesquisadores. Os últimos tiveram a oportunidade de contar suas histórias relativas às experiências vivenciadas na formação inicial e, a partir dessas histórias, emergiram indagações, discussões e reflexões, constituindo, assim, um espaço formativo.

O período em que foi desenvolvida essa experiência coincidiu com a vivência dos estágios curriculares supervisionados e, nesse sentido, as narrativas dos licenciandos foram significativamente marcadas por tal experiência, muito embora não se limitassem a elas, abarcando outras experiências que foram relevantes ao longo de todo o curso.

Colaboraram com a pesquisa, quatro licenciandos de um curso de Licenciatura em Física, todos jovens trabalhadores que já sobreviviam às suas próprias expensas, com idade entre 22 e 30 anos, sendo três do sexo masculino e uma do feminino. Todos eles residiam em Pontes e Lacerda, município do interior do estado de Mato Grosso, distante quatrocentos e cinquenta quilômetros da capital, Cuiabá. Trata-se de uma região que tem sua base econômica na pecuária e na extração de minérios, sendo a oferta de ensino superior bastante reduzida. Com o intuito de preservar a identidade dos participantes, previamente aprovados pelos mesmos, assim como por ética, foram eles nominados com as letras "LF", fazendo referência a "licenciandos em Física", seguidas de numerais de 1 a 4, que corresponde ao número dos participantes.

Suas narrativas são carregadas de sentidos construídos ao longo da experiência vivenciada e das reflexões potencializadas nos encontros de discussões, coletivas e individuais. Por questão de delimitação de tempo e espaço, foram incorporadas reflexões relativas ao processo de percepção de si mesmos como futuros professores, as significações e ressignificações que ocorreram ao longo desse processo, caráter inicial e processual da construção de suas identidades profissionais docentes.

Foram tomados como suporte teórico de sustentação das composições de sentido, as discussões sobre os processos de construção identitária (NÓVOA, 2007; MOITA, 2007; BOLIVAR, 2007; GARCIA, 2009), uma vez que as discussões sobre identidade docente não podem estar desvinculadas daquelas relativas à formação de professores (GARCIA, 1998, 1999, 2009; NÓVOA, 1992; IMBERNÓN, 2010; MIZUKAMI et al., 2006), uma vez que é por meio dessa dinâmica que são compostos os espaços formativos construtores das identidades profissionais dos professores (MOI- 
TA, 2007, p. 115). Assim, formação e identidade docente, embora sejam conceitos distintos, estão imbricados e não podem ser dissociados, possibilitando, justamente, refletir a partir dessa conjunção "formação-identidade".

Partindo do entendimento de que a formação dos professores é processual e contínua, visto nunca acabada, mas sempre em movimento, ela é influenciada por múltiplos processos e contextos, com dimensões subjetivas e intersubjetivas (GARCIA, 1999, 2009; NÓVOA, 1992; IMBERNÓN, 2010; MIZUKAMI et al., 2006), sendo as identidades constituídas, significadas e ressignificadas no processo no/do qual vão se nutrindo. Sendo assim, não constituem, de pronto, um único e determinado momento do processo formativo.

No entanto, compreende-se que determinados períodos podem se tornar expressivamente potencializadores dessas significações identitárias ao longo da carreira (BOLIVAR, 2007). No presente artigo, objetiva-se discutir um desses períodos: o da formação inicial.

Ao longo dos dois semestres em que os licenciandos foram acompanhados, pode-se perceber, a partir de suas narrativas, que conforme se envolviam nas experiências formativas e construíam aprendizagens profissionais, suas percepções identitárias também passaram por significações e ressignificações. Pode-se dizer, então, que os licenciandos foram construindo uma imagem "de si mesmos enquanto profissionais" (GARCIA, 2009, p. 112), à medida que o curso avançava e lançava novos desafios, novas experiências e aprendizagens, sendo o marco decisivo para essa construção identitária os estágios curriculares supervisionados.

Para compreensão desse processo, foram observadas as narrativas dos licenciandos que apresentaram as motivações que os levaram ao curso de licenciatura em Física:

Vim para o curso de Física, licenciatura em Física, porque a minha mãe me inscreveu e pagou a inscrição sem eu saber e depois disse que se eu passasse no vestibular não precisaria devolver o dinheiro, mas se não passasse, teria de devolver. Daí eu pensei: pelo menos vou passar e iniciar o curso para não precisar devolver, depois eu vejo se continuo (risos). Eu não sabia muita coisa sobre o curso, sempre gostei da área das exatas, mas não sabia que era um curso para ser professor, para formar professor. Quando fiquei sabendo do resultado do vestibular foi uma alegria, enfim eu iria iniciar uma faculdade que tanto minha mãe queria e eu também queria, para ter um futuro mais promissor. (LF1).

Na verdade, eu não optei pelo curso de licenciatura em Física, eu fiz porque eu tinha acabado de ganhar minha filha e eu queria fazer uma faculdade e era o único curso noturno, então passei e entrei. (LF2). 
[...] nesse curso, eu entrei porque não tinha nada pra fazer mesmo. Eu terminei o ensino médio, eu queria continuar e não tinha nada de outro curso. Fiquei sabendo do curso aqui de Física, numa palestra que a gente veio aqui, daí eu me interessei porque eu sempre tive mais atenção pela área de exatas, matemática, Física, essas coisas. (LF4).

Bem, eu acho assim, que esse processo de formação ele [...] até no início a gente fala assim; 'ah eu cai de paraquedas, não tinha outro curso pra fazer'. Eu acredito que eu fui um dos poucos aqui que realmente queria fazer o curso de Física. O curso apareceu em um momento que eu precisava voltar a ter desafios mentais de aprendizagem e crescimento pessoal. Optei pela Física, pois sempre gostei das ciências da natureza, do contexto homem-natureza e desenvolvimento intelectual. Não tinha a intenção de ser professor, queria fazer Física, "a Física”. (LF3) (informações verbais).

As narrativas dos licenciandos revelaram, em primeiro lugar, que a decisão de prestar o vestibular e ingressar no curso estava, fundamentalmente, vinculada à vontade de continuar os estudos, justificada por LF1 como condicionamento para "um futuro mais promissor". Essa vontade esbarrava no fato de todos já exercerem um trabalho que, de certa forma, os fixava na região onde residiam, e o curso, recém-aberto, atendia às necessidades desses jovens trabalhadores: um curso em instituição pública, noturno e que não exigia grandes deslocamentos. Somou-se a isso certa afinidade com a área de estudos e, daí, a "opção" por cursá-lo.

Nessa perspectiva, Gatti et al. (2010), ao discutirem fatores de atratividade para as profissões em sentido geral, para então discutirem a atratividade para a profissão de professor, apontam para pesquisas que sinalizam que mesmo com uma multiplicidade de possibilidades de escolhas profissionais existentes na atualidade, quando se analisa a realidade das escolhas, considerando-se os contextos, assim como as realidades e prioridades desses jovens, as escolhas tornam-se limitadas, uma vez que estão além das contingências do mercado de trabalho e sinalizam para múltiplos fatores, que vão desde expectativas familiares até aquilo que se apresenta mais viável para o jovem, na realidade em que vive (GATTI et al., 2010, p. 143). Foram detectadas aproximações destas discussões com as histórias dos licenciandos, uma vez que suas escolhas estiveram muito mais condicionadas por aquilo que era viável no contexto em que estavam, do que propriamente por uma decisão deliberada pelo curso. A opção por um curso profissional - e, no caso específico, a opção pela licenciatura - ocorreu no movimento e no contexto do viver, nos condicionamentos que demarcaram a experiência de vida de cada um, naquilo que era possível para o momento e contexto em que viviam. 
A afinidade com a área de conhecimento do curso, no caso de LF1, LF3 e LF4, foi, também, fator que acabou por reforçar as decisões. A perspectiva de ter viabilizada a vontade de continuar os estudos, calcada na ideia de que eles podem significar um futuro mais promissor, no sentido da ascensão social, sobrepõe-se a desejos outros, no que se refere à busca por uma profissão. Por outro lado, a perspectiva da formação de professores, uma vez que se tratava de um curso de Licenciatura, não era, a priori, conscientemente assimilado pelos jovens candidatos ao curso, como pode ser ilustrado em suas falas.

Entre a decisão em entrar para o curso, realizando o desejo de "continuar os estudos", "fazer uma faculdade", ou "ter novos desafios mentais e de aprendizagem", e a tomada de consciência de que se tratava de um curso de licenciatura, cujo foco é a formação do professor, muitas tensões se estabeleceram. Os licenciandos vão revelando como foram trabalhando essa perspectiva e como foram construindo sentidos sobre a experiência formativa na qual estavam envolvidos:

Porque eu nunca pensei em ser um profissional da educação, nem me passava pelas ideias [...] o tanto que eu dei de trabalho para os professores na época de escola, não quero sofrer nada disso agora (risos). Mas assim, primeiramente quando eu entrei no curso, achei que era totalmente diferente, disseram que era um curso de Física, mas tá, era LICENCIATURA (ênfase) em Física. Só que eu não tinha essa ideia de "o que é uma licenciatura", que no caso vai sair formado professor. Antes eu pensava: $\mathrm{Ah}$ ! vou fazer uma faculdade de Física, nada a ver com sala de aula, eu vou fazer uma faculdade. E com o decorrer do curso, com as matérias didáticas e com tudo voltado para o ensino, foi despertando um pouco o interesse de, tipo assim, não "o interesse" $[\ldots]$ como vou explicar, como vou dizer (pausa) [...] abriu a mente para o que realmente o curso estava proporcionando, ou até onde é que ele estava levando a gente, que seria essa formação profissional para nos tornarmos aptos a lecionar em qualquer escola de ensino médio, ou ensino fundamental. Não era minha intenção ser professor. Quando eu entrei na faculdade, mas no decorrer do curso, quando fui trabalhar algumas aulas de reforço com os alunos do IFMT, despertou um pouquinho de interesse em ser professor. Não quer dizer que eu serei professor quando terminar o curso, mas não descarto essa possibilidade tanto pela profissão, que é uma ótima profissão, mas também pela questão financeira. (LF1).

Nesta época pensava que sairia um cientista e não professor de Física. Penso que essa transição foi uma das mais árduas tarefas durante toda a graduação. Afinal, todos rejeitavam a ideia de estarem se graduando para se tornarem professores, ainda mais com a divisão existente entre os professores das exatas e humanas do próprio curso. No decorrer do curso, pouco a pouco foi formando a identidade de professor, e com isso cau- 
sava ainda mais temor ao pensar que um dia estaríamos em uma sala de aula. Como proceder? Seria nossa formação suficiente para estarmos à frente de uma classe? Inquietudes que foram dissipadas apenas com o término do estágio de regência. E eu acho que a maior dificuldade mesmo, no curso, é aceitar que o curso é de formação de professores. Eu acho que essa foi a maior dificuldade para todos os alunos, no sentido de: ah! Eu to aqui para me formar professor. Porque até mesmo quando você vê esse processo, quando a gente entrou, quando a gente iniciou, ainda dá uma resistência. Até mesmo comigo, quando me perguntavam: você está fazendo o que? ' - “Ah! Eu faço Física". “-Mas, é para ser professor?"- "É [...] também”, a gente fala assim "também" (risos). E acaba não dizendo assim: Estou sendo formado pra ser professor, porém eu posso fazer outras coisas. Não, o "professor" vem depois, fica para depois. (LF3).

Não tinha a intenção de ser professor porque a princípio tinha o pensamento de que veria apenas Física pura e futuramente iria virar um pesquisador na área. (LF4) (informações verbais).

A negação da pretensão profissional pela docência se evidencia, nas narrativas de LF1, LF3 e LF4, pelo uso das expressões: "Porque eu nunca pensei em ser um profissional da educação [...] Não era minha intenção ser professor” (LF1), "todos rejeitavam a ideia de estarem se graduando para se tornarem professores" (LF3), "Não tinha a intenção de ser professor” (LF4) (informações verbais). Suas falas remetem à compreensão de que, ao chegarem ao curso, não tinham muita consciência de que se tratava de um curso de formação de professores, visto que suas expectativas se voltavam para os conhecimentos específicos da disciplina, sendo a formação do pesquisador cientista a imagem profissional que trouxeram para o início do curso. LF1 indicou, ainda, que sabia que era uma licenciatura, mas que não tinha muita noção do que isso exatamente significava.

A pouca atratividade pela carreira docente e a recusa por aqueles que se encontravam nos cursos de formação de professores é um problema recorrente nas pesquisas, no Brasil e no mundo (GATTI, 2010, 2014). O desprestígio social da profissão, dificuldades de progressão na carreira, baixa remuneração, precarização das condições de trabalho são alguns dos fatores que têm levado a uma crescente diminuição do interesse pela profissão, o que projeta um cenário similar em muitas regiões, a falta de professores para atender, principalmente, a educação básica.

Por outro lado, no decorrer do curso a questão da docência vem à tona e eles, de certa forma, se veem obrigados a pensar sobre ela, mesmo que isso signifique - como apontado por LF3 - um processo de transição muito difícil, "uma das mais árduas tarefas." Emblemática a reflexão de LF3 quando afirma que, ao ser interpelado 
sobre o curso que estava frequentando, afirmou ser "Física", numa clara tentativa de encobrir, camuflar ou esconder a perspectiva da docência, deixando a ideia do "professor para depois". Subentende-se que o status social derivado do fato de estarem cursando uma graduação tenderia a ser ofuscado se o curso fosse de formação de professor. Ser "físico" teria muito mais impacto perante a sociedade do que ser "professor de Física", por isso o "professor" vem depois, fica para depois.

$\mathrm{Na}$ esteira desse movimento, a construção de uma identidade profissional, ainda em seu processo inicial, sofreu as marcas da resistência e da negação. Mesmo que, com o decorrer do curso, algumas novas percepções fossem construídas em sentido afirmativo à profissão, visto que, frente às experiências vivenciadas, a necessidade de afirmar que isso "não quer dizer que eu serei professor" (LF1), denota que as tensões e conflitos estão ainda muito latentes.

Nesse sentido, Nóvoa (2007, p. 16) entende que a "identidade não é um dado adquirido, não é uma propriedade, não é um produto. A identidade é um lugar de lutas e conflitos, é um espaço de construção de maneiras de ser e estar na profissão." Os licenciandos, vivenciando as lutas e conflitos, buscam a compreensão de si mesmos no interior da vivência em formação acadêmica, e, aos poucos, constroem uma autoimagem de professores, visto constituir uma maneira de "ser e estar na profissão", que não é aquela que tinham imaginado, mas que o curso, de certa forma, condicionou-os a assumir, mesmo que provisoriamente. Ainda nesse sentido, Nóvoa (2007, p. 16) sinaliza que em razão do caráter processual que demarca a construção das identidades profissionais, "é mais adequado falar em processo identitário, realçando a mescla dinâmica que caracteriza a maneira como cada um se sente e se diz professor." Assim, com o passar do tempo, os licenciandos, em seus processos de construção identitária, vão revelando como descobrem, percebem e sentem “o ser professor”.

Importante considerar que todos os licenciandos já estavam imersos no mercado de trabalho e já desempenhavam atividades que lhes garantia o sustento. A construção de uma identidade profissional, nessa perspectiva, implica considerar que eles ingressaram em um processo formativo que lhes exigiria uma grande reestruturação e ressignificação identitária, e que assumir a profissão de professor implicaria o rompimento com a atividade que já vinham desempenhando e na qual já encontravam alguma segurança, pela experiência já adquirida, trocando por outra atividade profissional sobre a qual tudo era novo e incerto. Como fica entendido na fala de LF4, logo no início da pesquisa: "Ainda não sei se vou exercer a profissão, porque já trabalho em uma área que me fascina muito e, talvez, não venha a mudar de área por enquanto.” (informação verbal). 
Dentre os licenciandos, um deles destoou quanto à compreensão do processo no qual estava se envolvendo, em virtude de que já tinha desempenhado atividades docentes como professora substituta - mesmo sem formação para isso - em sua cidade. Também, suas experiências familiares lhe proporcionaram outro olhar sobre essa realidade, como pode ser observado em sua narrativa:

Então, na minha vida eu sempre tive influências de professores, sempre vivi em meio a professores na minha família. E, até então, eu sempre dizia que eu seria professora, mas, depois de um tempo eu tinha mudado essa opinião. Eu acho que eu me levei um pouco pelo respeito grande que eu tenho pelas minhas tias que são professoras, elas praticamente me criaram. Então, eu acho que eu idolatrei aquela imagem da minha tia professora e assim eu dizia: eu também vou ser professora. Mas aí o tempo passou e foi passando, passando e eu tinha me esquecido. Só que quando eu comecei a fazer o ensino médio, quando eu estava no segundo ou terceiro ano eu comecei a participar mais da vida escolar lá, porque a minha mãe trabalha na escola e tal e a gente era bem envolvido com a escola e eu comecei a dar aula lá na escola que eu estudava, com substituição no ensino médio, na creche e então eu voltei a esse meio dos professores de novo. E assim, todo mundo me tratava como professora lá na escola, porque eu ficava meses lá dando aula como substituta. E assim, claro que eu me encontrei, na verdade, nessa profissão porque é uma coisa gostosa. Pra mim, eu acho gostoso ensinar e tal [...]. Então assim, quando eu entrei pra faculdade eu não imaginava que, na verdade, eu seria mesmo professora. Quando eu fui fazer a inscrição, o único curso que tinha à noite era Física, mas até então eu não tinha prestado atenção que era licenciatura. Eu fiz e depois que eu parei para analisar que seria para professora, eu disse: olha aí, voltando lá na minha adolescência quando eu dizia que iria ser professora (risos) e eu vou acabar fazendo um curso para ser professora mesmo. E o curso na verdade, me ajudou bastante a tomar essa decisão mesmo no real, para o ensino. (LF2) (informação verbal).

Mesmo que a opção pelo curso não tenha sido feita em um primeiro momento, com a consciência de que se tratava de um curso de formação de professores, e que este se apresentou como a opção viável em um momento em que assumia a maternidade, LF2 trabalhou de maneira muito mais tranquila a descoberta de que tinha ingressado em um curso de formação de professores. Os conflitos pessoais foram mais tênues em relação à realidade formativa em que se engajava, sendo bem aceita desde o início a possibilidade de assumir a docência como profissão. Certamente, as influências familiares e as experiências como professora substituta contribuíram para que LF2 construísse uma percepção diferenciada de seus colegas, e sobre a profissão e a percepção de si mesma como professora. São notórias as aproximações da realidade que caracteriza LF2 com as proposições de Garcia (2009, p. 109), para quem "a 
identidade profissional docente se constitui como uma interação entre a pessoa e suas experiências individuais e profissionais."

Portanto, a identidade profissional não é algo fixo ou estático e "que se possua", mas é dinâmica e evolutiva, no sentido que está em permanente processo de desenvolvimento. Também não é atributo da individualidade de uma pessoa, e sim um fenômeno relacional, portanto, acontece no terreno do intersubjetivo.

Por outro lado, as experiências vivenciadas no período do estágio, momento das primeiras vivências da prática profissional, mesmo que ainda não sejam experiências de efetivo exercício profissional, com todos os seus caracterizadores e as suas particularidades, acaba por desencadear, nos licenciandos, significativas reflexões e ressignificações quanto à profissão de professor.

As atitudes de negação do ser professor, que caracterizaram o discurso inicial dos licenciandos, tomou outra perspectiva, não no sentido de assumir a possibilidade da profissão, mas no sentido de que o momento formativo exigiu que eles dessem sentido para a experiência vivida. Vai se construindo a percepção de um momento de transição em que se encontram: de alunos, que sempre se viram, passaram a trabalhar com a perspectiva de se tornarem professores, mesmo que fosse apenas para cumprir as exigências que a etapa formativa lhes impunha. Essa transição foi marcada por diferentes sentidos, conflitos, percepções, mas traduzem a instabilidade que o "ser aluno" e "ser professor" ao mesmo tempo se lhes apresentava: "[...] lá na escola, a gente estava como professor, mas a gente sabia que a gente também era aluno." É nesse sentido que a identidade profissional "é uma construção que tem a marca das experiências feitas, das opções tomadas, das práticas desenvolvidas, das continuidades e descontinuidades, quer ao nível das representações, quer ao nível do trabalho concreto.” (MOITA, 2007, p. 16).

LF3 demarca bem essa passagem, ressaltando que a experiência é de tal forma significativa que sua vivência implicará mudanças significativas na sua percepção sobre o "ser professor":

\footnotetext{
Várias são as sensações experimentadas neste processo, agradáveis ou não, mas todas fazem parte da aprendizagem de um futuro profissional. O estágio supervisionado pode ser considerado também como um momento de transição, ou inversão de papel como defendem alguns autores, pois o licenciando inicia suas visitas à escola como um discente e acaba o estágio com outro olhar, o olhar de um professor. Toda sua atuação durante esta fase vai se direcionando até que atinge este ponto e, certamente, jamais será o mesmo que iniciou o processo. (LF3) (informação verbal).
} 
De aluno a professor, LF3 aponta para o que considera ser as novas atribuições assumidas nessa transição:

Apesar de estarmos no decorrer do curso o tempo todo tendo contato e, por consequência, observando a atuação dos professores, isso não implica exatamente o vivido no decorrer do estágio, pois estamos com outro olhar, o olhar de um futuro professor e não o de um aluno que está em sala para observar uma aula direcionada a ele. E nesse contexto, sempre se pensava o que faríamos, como atuaríamos nas situações apresentadas em sala de aula. Agora, possivelmente, algumas destas situações poderão concretizar-se e caberá a nós tomarmos as decisões necessárias para isso, assumindo o lugar daquele que tempos atrás foi criticado por certas posturas. Mas como atuar nesses casos? Qual postura tomar? Teoricamente trabalhamos esses temas, pois tivemos disciplinas destes cunhos no decorrer de nossa formação. Talvez agora vejamos o quanto são importantes na grade curricular e daremos o seu devido valor. Entretanto, elas por si só não salvarão ninguém dos apuros e dificuldades apresentados, mas poderão subsidiar as decisões cabíveis para tais. (LF3).

A realização do estágio supervisionado é a oportunidade da práxis, do contato com a dinâmica escolar, com o que ela representa, os valores sociais que a escola representa para a comunidade, pois afinal o licenciando está assumindo o papel de um professor e tudo o que ele representa naquele meio, ressaltando que o mesmo não deve imitar o mesmo, mas ir além, pois o que se espera que este seja consciente de suas ações como educar, ainda que naquele pequeno instante. (LF3).

Os novos sentidos construídos por LF3 sobre a profissão, que demarcam sua percepção do momento de transição identitária pelo qual está passando, vão ao encontro da compreensão de identidade profissional de Garcia (2009, p. 112), para quem a identidade profissional não é "uma identidade estável, inerente, ou fixa. É o resultado de um complexo e dinâmico equilíbrio onde a própria imagem do profissional tem de se harmonizar com uma variedade de papéis que os professores sentem que devem desempenhar." No decorrer da experiência, vai se dando conta das responsabilidades que terá de assumir como profissional e, mesmo com muitas dúvidas sobre como conseguiria ou não encarar com êxito essas novas responsabilidades, construiu o entendimento de que precisará assumir com autonomia essas responsabilidades e encontrar os caminhos necessários para o bom desempenho, mobilizando os conhecimentos que construiu ao longo do processo formativo.

Por sua vez, para LF4, a experiência do estágio marcou a sua volta à escola, onde fora aluno durante o ensino médio, pois a transição de aluno para professor adquiriu importância ainda maior e exigiu um processo de nova adaptação: 
No meu primeiro dia na escola como estagiário, procurei observar como iria ser a rotina durante o período que iria permanecer na escola, para isso observei a chegada dos alunos e o comportamento deles durante o período do intervalo. Esse processo ajudou para minha adaptação naquele local, pois naquele momento eu estava retornando com um papel totalmente diferente, em relação ao momento que frequentei aquela escola na condição de aluno. (LF4).

Quando a gente é aluno, a gente passou por tudo isso, observar a aula, a gente participa e tudo, a gente já conhece tudinho. Mas quando a gente começa o estágio a gente começa com uma responsabilidade diferente em relação à turma de alunos. A gente é aluno, mas é diferente daqueles alunos que estão lá dentro da sala. A visão que a gente tem de quando é aluno para agora é bem diferente. Uma coisa que eu procurei ver lá foi a postura do professor, de como a gente pode se portar em sala de aula, do trabalho. (LF4) (informações verbais).

Nesse período de transição, sua postura foi muito marcada pela observação, na tentativa de construir outra postura diferenciada daquela de quando foi aluno na mesma instituição. A tensão vivenciada por LF4, nesse período de transição, exigiu-lhe desconstruir uma visão de escola - e daquela escola específica, porque a vivenciou por muito tempo enquanto aluno - e de si próprio como aluno, para, então, compreender-se, e à escola, sob nova perspectiva. Sua estratégia foi a observação em busca de referências constituídas no período em que cursava a escola, a concepção dos alunos e seus comportamentos, até a postura do professor.

Já LF1 demarcou seu processo de transição com a preocupação sobre as responsabilidades que experimentou com a nova função que assumiu na escola, agora como professor, e não mais como aluno:

O Estágio Supervisionado foi muito relevante não só para a minha formação acadêmica, mas também para eu ver como um professor, como é estar dentro de uma sala de aula, que até então eu só sabia como que era estar em uma sala de aula como aluno, notar as diferenças de responsabilidades de ser aluno e de ser professor, porque ali dentro da sala de aula você não tem compromisso somente com o aluno, você tem compromisso com a direção da escola, compromisso com os pais desses alunos, compromisso com toda a sociedade envolvida, porque ali você está formando um cidadão, muitas vezes a escola que mostra o caminho a ser seguido para o aluno que ali está, então ter esse contato com os alunos e a comunidade em geral é de suma importância para a boa formação docente. (LF1).

Sua narrativa se aproxima daquela de LF3, quando destacou as responsabilidades, percebidas como necessárias, ao assumir a condição de professor. Com- 
preendeu que a escola e o professor têm papel fundamental na formação do cidadão, chegando, muitas vezes, a assumir o papel de "mostrar o caminho a ser seguido pelo aluno" (LF1) (informação verbal). Com isso, entendeu que a responsabilidade e o compromisso da função profissional que estava a experimentar assumiam contornos muito importantes para toda a sociedade.

Todos acabaram por externar a ideia de que se tornar professor traz responsabilidades ampliadas, ressaltando o compromisso social da profissão, o que exige postura ética frente às exigências profissionais.

Por fim, ainda no calor das experiências vivenciadas e das reflexões construídas sobre as suas histórias, os licenciandos fizeram um balanço sobre os novos sentidos que construíram ao longo do processo. Sentidos carregados de insegurança, fragilidade na compreensão profissional, mas também da certeza de que se trata de um processo que é contínuo, e que eles se encontram ainda no início:

[...] uma coisa que eu não posso deixar de destacar é a importância que o estágio está tendo na construção de minha identidade como docente, pois quando eu fiz minha inscrição para o vestibular foi apenas para ter uma graduação, não importava qual, mas no decorrer destes três anos e meio ainda não tinha certeza se realmente eu queria ser professor porque até então não sabia como era ser um professor e o estágio me deu a possibilidade de ver na prática como é ser um professor. (LF1).

Hoje, dia 08 de novembro, um dia mais que especial: eu posso dizer que ser professora está no meu perfil: no primeiro dia que sentei para fazer o planejamento da minha aula para eu mesma estar lá na frente de uma turma comandada por mim. Então, assim, eu analiso o curso como assim [...] foi uma conclusão final mesmo para a minha decisão para ser professora, gosto muito e agora mesmo no estágio, não é uma coisa assim, que eu tive medo, porque como eu já dei aula eu já tinha um pouquinho de experiência. Eu só não sei se eu irei pra sala de aula logo que eu terminar, mas pretendo sim continuar atuando como professora sim. (LF2).

[...] porque eu sempre fico insistindo na ideia: "já que você se formou" [...] porque até mesmo como a minha cunhada me disse: "pelo menos experimente, você se formou para ser um profissional da educação, você também não pode sair" [...] como eu acho ridículo alguém dizer que não gosta de jiló se nunca experimentou jiló, então da mesma forma eu não posso dizer que eu não quero ser professor se eu nunca experimentei como é a vida de professor. E aí, também é o seguinte, a primeira experiência será, talvez, um terror, aí também tem um problema, que se a pessoa experimentar só superficialmente e aí: "Ah, é um terror, não quero mais" e não vai saber se depois poderia dar certo [...] é igual à casca do cajá-manga, o azedinho primeiro e só depois que você vai sentir o gosto (risos). (LF3). 
Ao final dessa etapa, posso concluir que o estágio foi de grande contribuição ao mesmo tempo me proporcionou muita satisfação. Pois notei que a prática docente é um exercício de aprendizagem constante. Por mais que a gente é estagiário a gente já é professor, já pode se considerar como professor, já pode ministrar a nossa aula, como aquele dia lá, já sozinho, né. (LF4) (informações verbais).

O conjunto das experiências ajudou-lhes a pensar os profissionais que queriam ser futuramente, caso assumissem o magistério, uma vez que as dúvidas quanto a seguir ou não na profissão persistiam, mesmo com as novas e significativas experiências vivenciadas.

Nesse sentido, entende-se que à medida que narravam suas histórias, os licenciandos acabaram por responder questões consideradas importantes, quando pensadas nos processos de construção das identidades profissionais: Quem fomos? Quem somos nesse momento? O que quero vir a ser? (GARCIA, 2009, p. 112). As respostas a tais questões são reveladoras de como os licenciandos foram construindo sentidos identitários relacionados à profissão para a qual estavam imersos em processos formativos.

\section{CONSIDERAÇÕES FINAIS}

Nossa intenção, ao apresentar as discussões da pesquisa desenvolvida com os licenciandos em seu contexto de formação inicial, foi dar mostras de aproximações com a pesquisa narrativa e a forma da condução das investigações no contexto do GEPForDoc. Nessa direção, a pesquisa narrativa apresenta-se como o referencial teórico-metodológico pertinente para as investigações no campo da formação de professores, uma vez que potencializa a interação por meio do diálogo, entre as dimensões individuais e socioculturais dos participantes da pesquisa, permitindo a ampliação da compreensão das múltiplas interações que se vão estabelecendo entre as diversas dimensões pessoais e formativas, as quais caracterizam os processos e percursos de desenvolvimento e aprendizagens profissionais dos professores.

Nesse sentido, as narrativas permitem uma compreensão mais global das intricadas relações dialógico/dialéticas dos contextos que envolvem os conhecimentos, as crenças, e os valores que se vão construindo/reconstruindo e mobilizando os percursos pessoais e profissionais dos professores, de modo a lhes conferir uma identidade pessoal/profissional ao longo de suas trajetórias.

Tomando as proposições de Clandinin e Connelly (1995, p. 11), de que "a razão principal do uso das narrativas na pesquisa em educação é que os seres humanos são 
organismos contadores de histórias, organismos que, individual e socialmente, vivem vidas contadas [...]" e que "[...] o estudo das narrativas são estudos da forma como os sujeitos experimentam o mundo", entende-se que se justifica a necessidade e relevância de tomar as narrativas para se compreender e construir sentido sobre os processos de desenvolvimento, aprendizagens e identidades profissionais dos professores, nas diferentes modalidades e etapas de seu desenvolvimento profissional. Trata-se da tentativa de compreensão do fenômeno, desde a perspectiva do participante da pesquisa, que assume, nesse caso, verdadeiramente, a condição de sujeito ativo, e narra desde a sua compreensão/experimentação de um mundo que se constrói e se reconstrói constantemente. É nesse movimento que a narrativa pode se converter em significativo espaço de formação-investigação para os professores, uma vez que, ao narrar suas histórias, ele é convidado a refletir sobre elas e ressignificá-las, conferindo-lhes sentido e significados outros, que não seriam alcançados não fosse o exercício narrativo.

A partir dessa perspectiva, ficou perceptível que os licenciandos em Física, participantes da pesquisa apresentada, passaram por dois momentos interessantes na construção de sentidos sobre o "ser professor": um primeiro momento marcado pela incerteza, pela negação e pela dificuldade em assumir-se enquanto futuros professores, e um segundo momento marcado por ressignificações quanto às suas percepções do “si mesmos profissionais docentes". Mesmo, ainda, com muitas dúvidas, incertezas e inseguranças quanto ao futuro profissional, os licenciandos foram influenciados pelas vivências e contatos com as escolas, com os alunos, com a necessidade de assumirem o papel de professor com todas as incumbências que isso implicaria, porém, por ocasião dos estágios, acabaram por desenvolver uma atitude mais proativa quanto à profissão.

Para finalizar, são ilustrativas as proposições de Garcia (2009, p. 112), pautadas nas discussões de Lasky, para quem:

A identidade profissional é a forma como os professores de-
finem a si mesmos e aos outros. É a construção do "si mes-
mo" profissional que evolui ao longo da carreira docente e que
pode achar-se influenciado pela escola, pelas reformas e pelos
contextos políticos, que "inclui o compromisso pessoal, a dis-
posição para aprender a ensinar, as crenças, os valores, o co-
nhecimento sobre a matéria que ensinam, assim como sobre o
ensino, as experiências passadas, assim como a vulnerabilidade
profissional".

A partir das considerações do citado autor, as identidades profissionais dos professores, a "construção do si mesmo profissional" exige um complexo contexto que se estende ao longo da carreira dos professores. Nessa perspectiva, o que foi discutido sobre os processos identitários dos licenciandos e suas construções identi- 
tárias são apenas sentidos iniciais, marcados pelas tensões das primeiras experiências e, ainda mais relevantes, sinalizados por grandes incertezas quanto a efetivamente assumirem a profissão. Entendeu-se, também, que o curso de licenciatura em Física possibilitou momentos mais efetivos de experiências, discussões e reflexões sobre a profissão de professor, de modo a contribuir com os seus processos identitários.

Por outro lado, ancorou-se na ideia de que o grande desafio foi o de compreender como os licenciandos - em tese futuros professores - foram compondo sentidos sobre o ser professor e como se perceberam enquanto "profissionais docentes", potencializando, enquanto formadores de professores, a pensar os processos formativos desses sujeitos, a repensar os cursos de formação inicial, de modo a ajudá-los a construir suas identidades profissionais sob uma perspectiva sólida, reflexiva e comprometida, o que os levaria, na eventualidade da inserção na carreira, a assumi-la com todo o comprometimento e com todas as exigências que se lhe caracteriza.

\section{REFERÊNCIAS}

BOLIVAR, A. La formación inicial del profesorado de secundaria y su identidad profesional. Estudios Sobre Educación, Navarra: Universidad de Navarra, n. 12, p. 13-30, 2007.

CLANDININ, D. J. Potentials and possibilities for narrative inquiry. In: CAMPBELL, M.; THOMPSON, L. (Ed.). Issues of identity in music education: Narratives and practice advances in music education. Charlotte, NC: Information Age Publishing. 2010. p. 1-11.

CLANDININ D. J.; CONNELLY, F. M. Pesquisa Narrativa: experiências e história em pesquisa qualitativa. Uberlândia: EdUFU, 2011.

CONNELLY, F. M.; CLANDININ, D. J. Relatos de experiência e investigacion narrativa. In: LARROSA, J. Déjame que te cuente. Barcelona: Editorial Laertes, 1995.

GADAMER, H. G. Verdade e método. Tradução Flávio Paulo Meurer. Petrópolis: Vozes, 1997.

GALVÃO, C. Narrativas em educação. Ciência e educação, Bauru, v. 11, n. 2, p. 327-345, 2005.

GARCIA, C. M. A formação de professores: novas perspectivas baseadas na investigação sobre o pensamento do professor. In: NÓVOA, A. (Org.). Os professores e sua formação. 2. ed. Lisboa: Publicações Dom Quixote, 1995. p. 51-76. 
GARCIA, C. M. A identidade docente: constantes desafios. Formação Docente, Belo Horizonte, v. 1, n. 1, p. 109-131, ago./dez. 2009.

GARCIA, C. M. Formação de professores: para uma mudança educativa. Porto-Portugal: Porto Editora, 1999.

GARCIA, C. M. Pesquisa sobre formação de professores: o conhecimento sobre aprender a ensinar. Revista Brasileira de Educação, Rio de Janeiro, n. 9, p. 51-75, 1998.

GATTI, B. et al. A atratividade da carreira docente no Brasil. Estudos \& Pesquisas Educacionais, São Paulo: Fundação Victor Civita, n. 1, p. 139-210, maio 2010.

GATTI, B. et al. Formação inicial de professores para a educação básica: pesquisas e políticas educacionais. Estudos em Avaliação Educacional, São Paulo, v. 25, n. 57, p. 24-54, jan./abr. 2014.

IMBERNÓN, F. Formação continuada de professores. Porto Alegre: Artmed, 2010 .

IMBERNÓN, F. Formação docente e profissional: formar-se para a mudança e a incerteza. 7. ed. São Paulo: Cortez, 2009.

MELLO, D. M. Histórias de subversão do currículo, conflitos e resistências: buscando espaço para a formação do professor na aula de língua inglesa do Curso de Letras. São Paulo, 2004. Tese (Doutorado em Linguística)-Pontifícia Universidade Católica de São Paulo, São Paulo, 2004.

MELLO, D. M. Pesquisa narrativa: fenômeno estudado e método de pesquisa. In: ROMERO, T. R. de S. (Org.). Autobiografias na (re)constituição de identidades de professores de línguas: o olhar crítico-reflexivo. Campinas: Pontes, 2010. p. 171-187.

MELLO, D. M. Pesquisa narrativa. Entrevista concedida a Aline Sieiro. Uberlândia, 30 abr. 2010. Disponível em: <http://www.alinesieiro.com.br/2010/04/30/ podcast-episodio-03-pesquisa-narrativa/> . Acesso em: 29 mar. 2014.

MIZUKAMI, M. da G. N. et al. Escola e aprendizagem da docência: processos de investigação e formação. São Carlos: EdUFSCar, 2006.

MOITA, M. da C. Percursos de Formação e de trans-formação. In: NÓVOA, A. (Org.). Vidas de professores. 2. ed. Porto-Portugal: Porto, 2007. p. 111-140. 
MOREIRA, M. A. Quebrando os silêncios das histórias únicas: as narrativas profissionais como contranarrativas na investigação e formação em supervisão. Formação Docente, Belo Horizonte, v. 3, n. 5, p. 11-29, ago./dez. 2011.

NÓVOA, A. (Org.). Os professores e sua formação. 2. ed. Lisboa: Dom Quixote, 1995.

NÓVOA, A. (Org.). Os professores e as histórias de suas vidas. In. NÓVOA, António. (Org.) Vidas de professores. 2. ed. Porto-Portugal: Porto, 2007. p. 11-30.

NÓVOA, A. (Org.). Professores: imagens do futuro presente. Lisboa: Educa - Instituto de Educação da Universidade de Lisboa, 2009.

NÓVOA, A.; FINGER, M. (Org.). O método (auto)biográfico e a formação. Natal, São Paulo: EdUFRN; Paulus, 2010.

SOUZA, E. C. (Org.). Autobiografias, histórias de vida e formação: pesquisa e ensino. Porto Alegre: EdiPUCRS, 2006.

TELLES, J. A. A trajetória narrativa: histórias sobre a formação do professor de línguas e sua prática pedagógica. Trabalhos em Linguística Aplicada, Campinas, v. 34, p. 79-92, jul./dez. 1999.

VAILLANTE, D.; GARCIA, C. M. Ensinando a ensinar: as quatro etapas de uma aprendizagem. Curitiba: UTFPR, 2012.

Artigo Recebido em: 14 de setembro de 2015 Aceito em: 21 de janeiro de 2016.

Endereço para correspondência: Fernando Corrêa da Costa, 2367, Boa esperança, 78060-900, Cuiabá, Mato Grosso,Brasil; filomena@ufmt.br 
